\title{
A CRIANÇA COMO SUJEITO NAS PESQUISAS EDUCACIONAIS - CONTRIBUIÇÕES DA SOCIOLOGIA DA INFÂNCIA
}

\author{
Nair Correia Salgado de Azevedo, José Milton de Lima \\ Universidade Estadual Paulista - UNESP, Programa de Pós Graduação em Educação, Presidente Prudente, SP. E-mail \\ nairazevedo@hotmail.com, miltonlima@fct.unesp.br
}

\section{RESUMO}

O tema dessa pesquisa qualitativa de doutorado, do tipo etnográfico, relaciona-se à produção das culturas lúdicas infantis nos contextos escolares mesmo com muitas formas de cerceamento do lúdico por meio do corpo e da relação de poder entre adultos e crianças nas escolas. Tem como um dos objetivos perceber a criança como sujeito em pesquisas acadêmicas, utilizando-se da sociologia da infância como norteador teórico. Nesse estudo, concluiu-se que as crianças elencam os jogos e as brincadeiras como elementos importantes das culturas infantis dentro da escola, pois auxiliam no processo escolar tanto em aspectos relacionais quanto no processo de produção cultural da infância, o que implica enxergar as práticas lúdicas escolares como um direito. Concluímos também que o professor mediador faz a diferença nesse contexto e por meio dele existem possibilidades de articular ações que promovam as culturas infantis.

Palavras-chave: Infância. Ludicidade. Etnografia. Sociologia da Infância. Culturas Lúdicas Infantis.

\section{CHILD AS A SUBJECT IN EDUCATIONAL RESEARCH - SOCIOLOGY OF CONTRIBUTIONS OF CHILDHOOD}

\begin{abstract}
The theme of this qualitative research doctorate, the ethnographic, relates to the production of children's ludic cultures in school contexts even with many forms of playful curtailment through the body and the power relationship between adults and children in schools. It's one of the goals perceive the child as a subject in academic research, using the sociology of childhood as a theoretical guiding. In this study, it was concluded that the children we list the games and play as important elements of children's cultures within the school, as they help in the school process in both relational aspects as the cultural childhood production process, which involves seeing the playful practices school as a right. We also conclude that the facilitator makes a difference in this context and through it there are possibilities of joint actions to promote the children's cultures.
\end{abstract}

Keywords: Childhood. Playfulness. Ethnography. Sociology of childhood. Children's Ludic Cultures. 


\section{INTRODUÇÃO}

Pensar em pesquisas educacionais com crianças, a nosso ver, significa, num primeiro momento, mudança de paradigmas. Embora existam muitas discussões no meio acadêmico sobre a importância de se considerar as crianças como sujeitos ativos do processo de pesquisas acadêmicas para a infância, muito ainda há que se caminhar em direção ao reconhecimento das vozes infantis como dado científico dotado de todo rigor, planejamento e métodos que, por sua vez, gera a construção de conhecimento necessária para entendermos essa categoria geracional: a infância.

Para Saramago (2001), uma área que tem desempenhado um importante papel no sentido de considerar a importância das vozes infantis nas pesquisas acadêmicas com crianças, tem sido a sociologia da infância. Para a autora, a sociologia da infância atribui visibilidade às crianças que são, por sua vez, caracterizadas por um núcleo próprio, com relações intergrupais típicas e capazes de intervir socialmente pela própria experiência.

Essas relações intergrupais na qual Saramago (2001) se refere foi conceituada pelo sociólogo Willian Corsaro (2011), como "cultura de pares". O termo "pares" é específico para se referir ao grupo de crianças que passa grande parte do tempo juntas, quase todos os dias. A "cultura de pares", portanto, é definida pelo autor, conforme abordagem interpretativa, "como um conjunto estável de atividades ou rotinas, artefatos, calores e preocupações que as crianças produzem e compartilham em interação com as demais" (CORSARO, 2011, p. 128).

Segundo Corsaro (2011) embora as crianças desempenhem um importante papel na produção de rotinas culturais com os adultos, seja na família ou em outros ambientes, as atividades ocorridas com outras crianças e sua produção coletiva - que gera, consequentemente, uma série de cultura de pares - são tão importantes como a interação delas com os adultos. Isso porque a cultura de pares "é pública, coletiva e performática" (CORSARO, 2011, p. 128), e integram e contribuem para a cultura mais ampla de outras crianças e também dos adultos que estão a ela integradas.

Sarmento (2011) nos mostra que a expressão "ouvir a voz das crianças" condensa todo um programa teórico que constata o silêncio no qual as crianças foram historicamente submetidas. A sociologia da infância então tem se preocupado em estudar as crianças como atores sociais de pleno direito, analisando-as como categoria geracional.

Dessa forma, podemos perceber que realizar pesquisas com crianças significa se preocupar em realizar uma nova pesquisa, pois o reconhecimento da infância como categoria geracional, dotada de significados, com características próprias das identidades infantis, gera a preocupação com os métodos que delinearão tais estudos. Tal tarefa se dá pelo que Ferreira (2009) denomina como "novo paradigma da sociologia da infância", que sugere o abandono da criança objeto concebida por metodologias técnicas e tradicionais, o que implica penetrar no mundo das crianças e envolvê-las no processo de pesquisa buscando construir os conhecimentos com as crianças.

\section{METODOLOGIA}

Essa pesquisa do tipo etnográfica, de caráter qualitativo, foi realizada em uma unidade de educação pública municipal do Ensino Fundamental, no município de Presidente Prudente/SP. A unidade escolar atende crianças da Educação Infantil ao 50 ano do Ensino Fundamental, totalizando aproximadamente 375 alunos, situando-se na periferia da região oeste daquele município. É importante ressaltar ainda que a pesquisa passou pelo Comitê de Ética e Pesquisa da Faculdade de Ciências e Tecnologia - UNESP/Campus de Presidente Prudente, aprovada sob o protocolo de número $736.447 \mathrm{com}$ data de $01 / 08 / 2014$. Os dados foram coletados em duas turmas do 4으으 anos, no período de agosto a novembro de 2014 e também do período de março à setembro de 2015 , totalizando 50 crianças no total. 
A pesquisa ocorreu durante vários momentos no ambiente escolar, como a sala de aula, o recreio, as atividades que as crianças realizavam em oficinas pedagógicas, entre outros, pois um dos objetivos era perceber como se dava o processo de produção das culturas lúdicas infantis desse grupo de crianças.

As observações e anotações do diário de campo foram itens importantes dessa pesquisa, pois possibilitou o registro mais fiel possível sobre como essas vivências ocorriam no ambiente frequentado pelas crianças. Angrosino (2009) argumenta que a observação, para que seja mais objetiva, precisa absorver e registrar tudo com a máxima riqueza de detalhes possíveis. Trata-se de um trabalho árduo, mas o pesquisador precisa usar os cinco sentidos para que sua percepção esteja cada vez mais aguçada. Dessa forma, as anotações feitas em campo foram transcritas imediatamente, com o maior número de detalhes e descrições ambientais possíveis, o que nos auxiliou de forma relevante no momento de interpretação dos dados.

É certo que os métodos precisam sofrer uma adequação quando os atores do processo da pesquisa são crianças, como é o caso desse estudo. Um desses métodos, as entrevistas, ocorreram na maioria das vezes em grupo, pela estratégia que Saramago (2001) denomina de "entrevistasconversa". Trata-se de um método distinto da entrevista não estruturada e organizada em blocos temáticos. No caso desse estudo, a organização desses blocos temáticos iniciais foi definida com base nas anotações do diário de campo e das filmagens e fotos realizadas pelas crianças. A "entrevistas-conversa" não significa em nenhum momento um abandono do rigor científico, muito pelo contrário, trata-se de "uma técnica que implica um conjunto de preocupações adicionais na sua preparação, desenvolvimento e aplicação" (SARAMAGO, 2001, p. 14).

Todas as "entrevistas-conversa" foram gravadas em vídeo pela pesquisadora. Muitos autores como Saramago (2001), Azevedo (2012), Ventorin e Poleze (2010) consideram de extrema importância a familiarização com o equipamento de filmagem para que as gravações das entrevistas ocorram com mais tranquilidade. A primeira das "entrevistas-conversa" ocorreu após certo tempo de adaptação das crianças com a ação de filmar ou fotografar, portanto o processo de naturalização com o equipamento e as filmagens foi gradual e ao realizarem a primeira delas não houve nenhum problema relacionado à presença das câmeras.

Após as gravações, todas as "entrevistas-conversa" desse estudo foram transcritas em seguida e armazenados em HD externo. Além disso, as transcrições foram também impressas para que a consulta no dia-a-dia tivesse um caráter mais funcional. Dessa forma, a visualização se tornou mais eficiente e todos os demais procedimentos, como a conferência e triangulação dos dados, por exemplo, se tornaram mais práticas.

O uso de desenhos e/ou textos escritos pelas crianças também foram importantes para que elas tivessem várias opções para demonstrar suas opiniões e sentimentos. É possível perceber as visões das crianças através dos desenhos, pois aquelas mais tímidas poderão demonstrar seus pensamentos e ideias de outra forma que não seja a oral. Daí a importância de se utilizar vários métodos para coletar dados com crianças.

Ainda a respeito do uso de desenhos e textos, esse estudo adotou uma estratégia denominada por Saramago (2001) de "textos ilustrados". A dinâmica dessa técnica ocorreu da seguinte forma: iniciamos a conversa com as crianças e lançamos um tema registrando-o na lousa. Após receberem uma folha própria para desenvolver a atividade, tiramos as dúvidas que surgiram. As crianças então desenharam e escreveram sobre o tema individualmente, mas interagindo com os colegas caso quisessem. Durante a atividade, optamos por filmar o ambiente enquanto as crianças realizavam a proposta para tentar captar a essência social daquele momento. As crianças demoraram cerca de uma hora e meia a duas horas para realizar toda a tarefa. Houve pouca intervenção por parte da pesquisadora nesses momentos e as crianças tiveram total liberdade de escolha também dos materiais a serem utilizados. 


\section{RESULTADOS}

Apresentar a descrição de algumas impressões das crianças não é tarefa fácil e elencar apenas alguns entre vários registros que nos indicassem quais são as experiências mais significativas de produção das culturas lúdicas infantis desse grupo de crianças nesse contexto escolar, exigiu um poder de síntese que pudesse focar nesses significados, mas sem excluir nenhum detalhe importante.

Iniciaremos por aquela que percebemos ser uma das atividades que mais encontram resistência por parte de alguns professores no contexto de sala de aula, mas dotada de muita relevância pelas crianças: as atividades em grupo. Envolver as crianças nesse tipo de proposta significa sair da zona de conforto: movimentam-se as crianças e os móveis das salas, faz-se muito barulho, rompe com o silêncio tão cobiçado por muitos professores em suas aulas, dá bastante trabalho, pois promove muitos conflitos no início e até durante as atividades e, portanto, é o tipo de proposta pedagógica que muitos professores evitam realizar. Porém, as crianças enxergam nesse momento a possibilidade de se trabalhar em parceria com os colegas e, dessa forma, aproveitar para conversar também sobre outras coisas ampliando o conhecimento que já tinham, tanto em termos de conteúdos trabalhados na escola, quanto a conhecimentos relacionais ligados a seus colegas de sala.

As crianças participantes desse estudo também nos alertaram com relação ao falar e ser ouvido no ambiente escolar. O falar só é permitido na hora certa, o mover-se nem sempre é tolerado e o questionamento é visto como indisciplina. Além disso, as crianças muitas vezes se sentem "podadas" de tudo: não podem muitas vezes dizer o que pensam, são obrigadas a ficar imóveis sem questionar e, em muitos momentos, também são cerceadas do brincar nas escolas. Questionadas sobre como eram as relações entre eles mesmos nos anos anteriores e o que acontecia de legal na turma, uma das crianças participantes desse estudo respondeu: "Era sempre um atrás do outro fazendo lição".

Vemos então o quanto a afirmação de Oliveira (2006) é real: a escola é muito carrancuda e chata! "Se precisamos falar em alegria na escola, isso se deve ao fato de que a escola é malhumorada" (OLIVEIRA, 2006. p. 75). Ainda segundo a autora, a escola que conhecemos é cronometrada, com tempo muito maior para as atividades "sérias" e pouco tempo para as atividades de recreação - vivido exclusivamente nos poucos minutos de recreio, e sempre intercalado entre um trabalho e outro. Dessa forma, o compromisso firme é com a domesticação dos corpos e dos espíritos, tornando a escola uma instituição de constrangimento.

Outro dado que nos chamou a atenção é que em todas as formas utilizadas para a coleta dos dados apareceram de forma relevante a presença do movimento e das relações sociais como fatos importantes para as crianças no ambiente escolar. Em uma das "entrevistas-conversa" realizada com as crianças, quando o assunto foi as filmagens feitas por elas, ficou evidente a preferência por filmar ações ocorridas fora do contexto de sala de aula. No caso das filmagens feitas, por exemplo, na "Quadra", em que o contexto era bastante diversificado, a justificativa das crianças por filmar um ambiente tão complexo e atraente ao mesmo tempo, foi o sentimento de liberdade que usufruíam quando estavam neste local, mesmo sendo, algumas vezes, cerceados pela privação do movimento.

Nas tentativas que temos, muitas vezes, de privar as crianças dos movimentos, não percebemos o quanto essas proibições afetam as relações que ocorrem dentro das escolas. Porém, ao perceberem tais oportunidades de se expressarem, as crianças tentam aproveitar o máximo que podem, e isso é perceptível na fala de uma das crianças ao dizer "Lá a gente pode fazer qualquer coisa, brincar, aqui (sala de aula) não, lá não tem lição".

Se é se movimentando que as crianças criam, recriam, produzem sentidos em seu cotidiano e experimentam diferentes formas de interpretar o que acontece em sua realidade, temos que nos atentar às brincadeiras que ocorrem no contexto escolar enquanto as crianças 
podem usufruir delas. As crianças desse estudo nos mostraram como ocorre a produção dessas culturas lúdicas por meio das brincadeiras de várias formas, e uma delas foi por meio do "Diário de Brincadeiras Coletivo" que as crianças levavam para suas casas e poderiam escrever o que quisessem nele sobre suas preferências. Foram muitas as percepções demonstradas nesse momento, como a satisfação em produzir e compartilhar suas experiências individuais com a cultura lúdica infantil construída em grupo na escola por esse grupo de crianças.

Já no "Texto llustrado", em que as crianças foram indagadas diretamente sobre quais situações e experiências durante a trajetória de vida escolar foram, para eles, mais significativa, cerca de $70 \%$ das respostas tiveram relações com jogos e brincadeiras no contexto escolar. No restante, $19 \%$ foram relatos envolvendo festas e $6 \%$ relacionados a atividades em sala de aula.

\section{CONSIDERAÇÕES FINAIS}

A maioria das escolas, hoje, trabalha contra as experiências lúdicas que as crianças podem produzir com seus pares nesse ambiente, ainda com a forte argumentação medieval de que o jogo e a brincadeira descontrolam nossas crianças, as deixam indisciplinadas, além de as práticas lúdicas estarem diretamente ligadas a áreas menos relevantes para alguns professores, pois os conteúdos "importantes" são aqueles que "fazem pensar", e para pensar é preciso silêncio, que precisa de atenção, que exige imobilidade e obediência. Uma verdadeira reação em cadeia!

Mas as crianças participantes desse estudo nos mostraram que é possível aprender em grupo, é possível compreender um processo sistemático científico arrastando mesas e cadeiras, é compatível o barulho das conversas com a aprendizagem significativa. Quando isso é permitido nossas crianças aprendem, pois a interação em sala de aula faz com que elas mesmas sintam-se mais à vontade para isso.

Uma das principais conclusões desse estudo está diretamente ligada à mediação do professor como um diferencial para propor experiências significativas que, por sua vez, incentiva o fluir e a produção da Cultura Lúdica Infantil no ambiente escolar. É essa mediação docente quem vai direcionar, muitas vezes, as ações, e essas podem pender para significações extremamente importantes e positivas ou, pode ser o contrário disso e, nesse caso, a criança vai preferir esquecer daquilo tudo e talvez, nunca mais querer qualquer tipo de contato com determinado conteúdo ou prática.

Os adultos, no contexto escolar querem em muitos momentos controlar a cultura lúdica infantil. O termo "cultura" foi durante muito tempo vista como "padrão" de poucos, imposto a muitos, e fazemos o mesmo hoje com relação à cultura de pares, por exemplo, dentro das escolas, quando tentamos acabar com as brincadeiras, quando pedimos silêncio o tempo todo, quando não ouvimos a opinião das crianças sobre muitas coisas, quando não as deixamos se mexer nas salas de aula, quando isso, quando aquilo. É a "Lei do não pode".

Como se não bastasse todas essas imposições, a cultura corporal nunca foi valorizada como um conhecimento digno de se fazer presente nos currículos. Não estamos falando daquele currículo elaborado do alto, que em poucas linhas diz de forma muito coerente que a cultura popular, incluindo as relacionadas ao corpo, deve estar presentes no contexto escolar, mas perguntamo-nos: como isso pode ser possível, se à criança muitas vezes lhe é exigido que entre nas escolas apenas com suas cabeças e que deixem, do lado de fora, seus corpos, como bem nos lembra Freire (1989). Algumas delas só faltam construir um guarda-volumes, daqueles que a gente vê em supermercados, para que deixe o "intruso" do lado de fora. E evitando a entrada desse "intruso" - o corpo - evita-se a entrada também de outro elemento "indesejável": o lúdico. 


\section{REFERÊNCIAS}

ANGROSINO, M. Etnografia e Observação Participante. Tradução: José Fonseca. In: FLICK, U. (Coord.). Coleção Pesquisa Qualitativa. Porto Alegre, Artmed, 2009, 138 p.

AZEVEDO, N. C. S. "Programa Cidadescola" no 1ㅇa ano do Ensino Fundamental em uma escola de Presidente Prudente: entre a ludicidade e a sala de aula. 2012, 213 f. Dissertação de Mestrado (Mestrado em Educação), Universidade Estadual Paulista - UNESP, Presidente Prudente, 2012.

FERREIRA. M. M. M. "Branco demasiado" ou... Reflexões epistemológicas, metodológicas e éticas acerca da pesquisa com crianças. In: SARMENTO, M. J.; GOUVEA, M. C. S. (Orgs.). Estudos da infância. Educação e práticas sociais. Petrópolis: Vozes, 2009, p. 143 - 162.

FREIRE, J. B. Educação de corpo inteiro. Teoria e prática da Educação Física. São Paulo, Scipione, 1989, 224p.

CORSARO, W. Sociologia da infância. Porto Alegre: Artmed, 2011, 384p.

OLIVEIRA, M. L. Escola não é lugar de brincar? In: ARANTES, V. A. (Org.). Humor e alegria na educação. São Paulo: Summus, 2006, p. 75 - 102.

ROCHA, R. A menina que aprendeu a voar. São Paulo: Moderna, 2012, 32 p.

SARAMAGO, S. S. S. Metodologia de pesquisa empírica com crianças. Sociologia, problemas e práticas, n.35, p. $9-29,2001$.

SARMENTO, M. J. Conhecer a infância: os desenhos das crianças como produções simbólicas. In: FILHO, A. J. M.; PRADO, P. D. (Orgs.). Das pesquisas com crianças à complexidade da infância. Campinas, Autores Associados, 2011, p. $27-60$.

VENTORIN, S.; POLEZE, G. M. L. Narrativas de imagens do recreio escolar. In: Encontro Nacional de Didática e Prática de Ensino. Convergências e tensões no campo da formação e do trabalho docente: políticas e práticas educacionais. Belo Horizonte, 2010, p. $26-37$. 